Políticas de discapacidad / accesibilidad en la UNLP

Sandra Lea Katz

Revista ES (en y sobre Educación Superior)

Vol.1, N¹-2 / Fecha de publicación: 27/12/2021

e-ISSN: $2718-6539$

https://revistas.unlp.edu.ar/ES/index

IIES - Facultad de Odontología

DOI: https://doi.org/10.24215/27186539e021

\title{
Políticas de discapacidad / accesibilidad en la UNLP
}

\author{
Disability / accessibility policies at UNLP
}

\section{Políticas de deficiência / acessibilidade na UNLP}

Licenciada Sandra Lea Katz

Directora de Inclusión y Discapacidad - Pro Secretaría de DDHH - UNLP

https://orcid.org/0000-0001-8110-9697

sandrakatz4@gmail.com

\section{Resumen}

La UNLP se presenta como institución pública, científica, extensionista, autónoma, cogobernada, inclusiva, popular y feminista. En este escrito 
tomamos todos estos atributos y nos apoyamos en el principio de la inclusividad para sumarle la cualidad necesaria de la accesibilidad. Nos proponemos compartir lo transitado y construido, ya que, desde la Dirección de inclusión, Discapacidad y DDHH junto a la Comisión Universitaria sobre discapacidad (CUD) desde hace 20 años se elaboran diferentes estrategias, políticas y prácticas que dan sentido a la posibilidad que cualquier estudiante con discapacidad pueda ser parte de la comunidad universitaria.

En la actualidad, al pertenecer a la Prosecretaría de Derechos Humanos se cuenta con la posibilidad y oportunidad histórica de poder institucionalizar las políticas necesarias y pertinentes para dejar instalado los requisitos y pautas necesarias donde la accesibilidad sea una política institucional y no quede dependiendo de la voluntad de algunes.

Las propuestas planteadas están en sincronía con declaraciones, documentos e intenciones tanto a nivel nacional a través de la Red Interuniversitaria de Discapacidad perteneciente al Consejo Interuniversitario Nacional (RID - CIN), como a nivel latinoamericano al ser parte activa y gestión de la Red Interuniversitaria Latinoamericana y del Caribe sobre Discapacidad y derechos humanos, vinculada a IESALC UNESCO.

\section{Abstract}

The UNLP presents itself as a public, scientific, extensionist, autonomous, co-governed, inclusive, popular and feminist institution. In this writing we take all 
these attributes and we rely on the principle of inclusivity to add the necessary quality of accessibility. We intend to share what has been traveled and built, since, from the Inclusion, Disability and Human Rights Directorate together with the University Commission on Disability (CUD) for 20 years, different strategies, policies and practices have been developed that give meaning to the possibility that any student with disabilities can be part of the university community.

At present, belonging to the Office of the Assistant Secretary for Human Rights has the possibility and historical opportunity of being able to institutionalize the necessary and pertinent policies to install the necessary requirements and guidelines where accessibility is an institutional policy and does not depend on the will. of some.

The proposed proposals are in sync with statements, documents and intentions both at the national level through the Interuniversity Disability Network belonging to the National Interuniversity Council (RID - CIN), and at the Latin American level by being an active part and management of the Latin American Interuniversity Network. and the Caribbean on Disability and Human Rights, linked to IESALC UNESCO.

\section{Resumo}

A UNLP se apresenta como uma instituição pública, científica, extensionista, autônoma, co-governada, inclusiva, popular e feminista. Neste escrito, pegamos todos esses atributos e nos baseamos no princípio da inclusividade 
para agregar a qualidade necessária de acessibilidade. Propomo-nos a partilhar o que foi percorrido e construído, pois, desde a Direcção de Inclusão, Deficiência e Direitos Humanos em conjunto com a Comissão Universitária de Deficiência (CUD) há 20 anos, foram desenvolvidas diferentes estratégias, políticas e práticas que dão sentido ao possibilidade de qualquer aluno com deficiência fazer parte da comunidade universitária.

Atualmente, por pertencer ao Gabinete do Subsecretário de Direitos Humanos, existe a possibilidade e a oportunidade histórica de poder institucionalizar as políticas necessárias e pertinentes para instalar os requisitos e diretrizes necessários onde a acessibilidade é uma política institucional e não depende na vontade. de alguns.

As propostas propostas estão em sintonia com declarações, documentos e intenções tanto em nível nacional por meio da Rede Interuniversitária de Deficientes pertencentes ao Conselho Interuniversitário Nacional (RID - CIN), quanto em nível latino-americano por ser parte ativa e gestora do país. Rede Interuniversitária Americana e o Caribe sobre Deficiências e Direitos Humanos, vinculada ao IESALC UNESCO.

\section{Palabras clave}

Discapacidad, educación superior, accesibilidad, derechos humanos.

\section{Keywords}


Disability, higher education, accessibility, human rights.

\section{Palavras chave}

Deficiência, ensino superior, acessibilidade, direitos humanos

La intención de este escrito es poder visibilizar, comprender y proyectar la posibilidad que cualquier persona que quiera ingresar a la universidad pueda hacerlo, en este caso el colectivo al que está pensado prioritariamente es el de las Personas con Discapacidad. Nos parece importante aclarar el prioritario, ya que la experiencia demostró, por un lado, que la discapacidad está invisibilizada, y por el otro, que cuando en clave de accesibilidad se hacen modificaciones en las prácticas, se benefician muchas más personas que la supuesta población destinataria: las personas con discapacidad.

Iremos analizando desde lo macro, con una mirada latinoamericana, para ir reduciendo el recorrido a lo argentino, para confluir y hacer foco en la Universidad Nacional de La Plata, describiendo y contextualizado lo trabajado en los últimos 20 años para dejar instalada las directrices que posibiliten la generación de condiciones institucionales que garanticen el acceso y permanencia de las personas con discapacidad en la Universidad, en sus diferentes dimensiones: Estudiantil, docente y nodocentes, desde la docencia, investigación, extensión y gestión. 
Realizar este escrito nos da la posibilidad de recordar, y aquí sí, en su versión etimológica de "volver a pasar por el corazón" (con el agregado de la intelectualización) de lo hecho en 20 años, nos permite compartir cómo fuimos lentamente comprendiendo y expandiendo la temática de la discapacidad / accesibilidad, descubriendo la complejidad de la misma.

Nos construimos junto a la voz de las personas con discapacidad (PcD), pero tratando de traducirla en una lógica de gestión institucional como es la UNLP con todas sus variables políticas, tratando de empatizar y lograr ser interlocutores confiables y creíbles con cada uno de los actores. Esto podría ser una de las razones por las que puede percibirse tan lento nuestro trabajo. Tan lento, pero tan consolidado, que hoy, casi sin darnos cuenta al mirar atrás vemos el avance que se logró instalar, a partir de cada problema, donde nuestra lógica era que cada situación y demanda individual debíamos pensarla y transformarla en un asunto político, en una lógica institucional.

Desde nuestros inicios, allá por 1999, no sabíamos cómo sería nuestro transitar. No había antecedentes. Decidimos optar por imaginar y propiciar espacios accesibles e inclusivos independientemente si en ese lugar, y en ese momento, había una persona con discapacidad dialogando con cada una de las áreas, tratando de generar empatía y trabajar en forma conjunta. Obviamente priorizamos

las urgencias, pero nunca dejamos de ver lo general al buscar respuestas en lo particular. Tampoco fuimos denunciativos, entendiendo que las acciones eran 
consecuencias de la ideología y los prejuicios que cada uno tenía en relación a las personas con discapacidad, y ante esto, había un sistema de creencias por el cual mucha gente ve a las Personas con Discapacidad como enfermos, merecedores de la caridad, de la asistencia y no portadores de derecho.

Comprendemos la discapacidad como una retórica cultural, como una construcción social, por lo tanto, iba a depender de cómo instalábamos los diálogos y la presentación de las situaciones conflictivas y discriminatorias para transformarlos en un escenario que invita a posicionarse como universidad pública.

La discapacidad es una cuestión de Derechos Humanos. No puede ser pensada

como un problema que vive (o lamentablemente "le tocó" a) la persona y su familia. La forma que esa persona y su familia viva su condición de discapacidad, dependerá entre muchas otras cuestiones por la formación / capacitación de los profesionales y la forma en que diseña políticas y lleva adelante sus prácticas.

Las acciones que fuimos aportando, junto a las dudas que iban surgiendo, las compartimos con otras universidades, tanto argentinas como latinoamericanas, retroalimentando las estrategias, y así es como hoy somos referentes de lo trabajado y logrado. Entendiendo que eso se debió a nuestro permanente intento de ser coherentes, sostener la perseverancia a pesar de las adversidades, implicancia y por sobre todo por estar convencidos que cualquier 
persona tiene el derecho a sentirse parte de la Universidad Nacional de La Plata.

Aunque el producto de este trabajo intenta ser una Guía que conlleve a una política institucional, en realidad creemos que esto debe interpelarnos, para revisar y revisarnos, en nuestras prácticas, políticas y acciones.

Creemos que todo trabajo en relación con la discapacidad/accesibilidad debe ser en forma colaborativa, junto a otros y otras. En este caso las personas con discapacidad, y que en general, prevalece la desinformación en relación a esta temática. Pero, una vez que se toma conocimiento de lo que se debería hacer y/o tener en cuenta ya pasamos de la desinformación a la discriminación.

En relación al trabajo vinculado al campo de la discapacidad se habla del modelo médico hegemónico y del modelo social, donde en el modelo médico la mirada está en relación al origen, que es determinada por una cuestión científica, y se cree que esa persona no tiene nada que aportar a la sociedad, que siempre debe estar bajo un proceso de rehabilitación bajo la mirada médica, quien decidirá y determinará hasta donde esa persona es capaz de realizar algo, en cambio desde el modelo social se plantea que la discapacidad se produce por una relación asimétrica de poder, de opresión social. No es la deficiencia lo que le impide a las personas con discapacidad acceder o no a un determinado ámbito social, sino los obstáculos y barreras que crea la misma sociedad, posicionando que es una cuestión de derecho de participar y decidir 
sobre lo que desea. Es en el modelo social que se postula el "nada sobre nosotros sin nosotros".

Adhiriendo a este posicionamiento, pensar en políticas universitarias, significa trabajar desde la lógica de la accesibilidad, motivo por el cual seguiremos hablando de la discapacidad en clave de accesibilidad. Reforzamos esta conceptualización: Discapacidad/accesibilidad en el aporte que nos hace Schmucler cuando refiere que "unas barras entre los dos términos articulan y destacan sus diferencias con una cópula. La barra, genera una fusión tensa entre elementos distintos de un mismo campo semántico...la barra acepta la distinción, pero anuncia la imposibilidad de un tratamiento por separado."

Desde un contexto latinoamericano, las políticas de accesibilidad/discapacidad son variadas, complejas, con realidades diferentes, pero también con muchas similitudes.

Principalmente varían las posibilidades de ingresar y permanecer en la educación superior, encontrando experiencias como las de Argentina y Uruguay, donde el ingreso es sin restricciones, o como las de Costa Rica y Colombia, que tienen políticas para que en las prueba de ingreso cuenten con los apoyos que requieren las personas con discapacidad, o Guatemala que tiene ingreso directo si acredita discapacidad, o Chile que depende de las convocatorias nacionales anuales para contar con los apoyos. Pero nos une la desigualdad, la idiosincrasia de las instituciones que no fueron pensadas para cualquiera, docentes que no cuentan con formación pedagógica y currículas 
que no tienen presenta la accesibilidad y, donde la mayoría de las experiencias están atravesadas por compromiso y voluntades individuales, sin presupuesto, pero con mucha creatividad.

En el año 2009 fuimos uno de los gestores, junto a la UBA y la red de Colombiana de instituciones por la discapacidad, para la conformación de la Red Interuniversitaria Latinoamericana y del Caribe sobre Discapacidad y Derechos Humanos (en adelante Red), donde logramos en estos años, que catorce países participen, y diez cuenten con redes / comisiones nacionales. Desde la UNLP, a cargo de la coordinación, asumimos el compromiso de sostener este espacio con diferentes líneas de trabajo, prioritariamente se recopilan experiencias de las políticas de las Universidades Latinoamericanas en relación a la discapacidad, "la red puede jugar un rol importante para promover, afirmar y difundir los derechos de las personas con discapacidad, generar e intercambiar conocimientos que posibiliten una mayor inclusión en la educación superior y apoyar el desarrollo de políticas de educación superior orientadas a eliminar la discriminación y barreras que enfrentan las personas con discapacidad". (Pérez, Fernández y Katz ,2013, p. 21). La UNLP también es la responsable de un boletín mensual digital, que desde 2014 ininterrumpidamente compila y difunde.

Podemos identificar dos hitos que marcaron cambios significativos en el contexto político: el Primer Seminario Regional sobre la inclusión de las personas con discapacidad en la Educación Superior en América Latina y el 
Caribe, celebrado en Caracas, Venezuela en diciembre del 2005 y al año siguiente la Declaración de la Convención Internacional sobre los Derechos de las Personas con Discapacidad de la organización de las Naciones Unidas. Esto generó movimientos y acciones en cada uno de los países, posibilitó que la Red, ya teniendo un marco legal pueda profundizar e intercambiar experiencias en relación a las transformaciones necesarias para llevar a cabo e implementar esas declaraciones.

La Convención Internacional sobre los Derechos de las Personas con Discapacidad de la Organización de las Naciones Unidas (CDPCD) fue aprobada por las Naciones Unidas en el año 2006, la mayoría de los países participantes la firmaron entre el 2008 y el 2017, siendo 173 los países signatarios. Argentina la ratificó con su protocolo facultativo bajo la ley 26378/08.

Rescatamos el Artículo $4^{\circ}$. Que refiere sobre las obligaciones generales:

1. Los Estados Partes se comprometen a asegurar y promover el pleno ejercicio de todos los derechos humanos y las libertades fundamentales de las personas con discapacidad sin discriminación alguna por motivos de discapacidad. A tal fin, los Estados Partes se comprometen a:

f) Emprender o promover la investigación y el desarrollo de bienes, servicios, equipo e instalaciones de diseño universal, con arreglo a la definición del artículo 2 de la presente Convención, que requieran la menor adaptación posible y el menor costo para satisfacer las necesidades específicas de las 
personas con discapacidad, promover su disponibilidad y uso, y promover el diseño, universal en la elaboración de normas y directrices...

A fines del año 2004, en la UNLP, se realizó una reunión de la ex Comisión Interuniversitaria sobre Discapacidad y Derechos Humanos (hoy Red Interuniversitaria sobre Discapacidad, perteneciente al Consejo Interuniversitario Nacional RID-CIN), donde los referentes de Universidades Nacionales argentinas junto a José Luis Parisi, Coordinador del Programa de Apoyo a Políticas de Bienestar- Secretaría de Políticas Universitarias (SPU) del Ministerio de Educación de la Nación, se acordó colaborar en la elaboración del documento argentino para presentar en el Primer Seminario Regional sobre la inclusión de las personas con discapacidad en la Educación Superior en América Latina y el Caribe, llevado a cabo en Venezuela a fines del 2005, dicho documento fue presentado por el Ministro de Educación Juan Carlos Pugliese. El evento fue el puntapié inicial de varias líneas: la visibilización de las políticas que se venían llevando a cabo en algunas universidades; el inicio de mesas de diálogos con la SPU y la Comisión Interuniversitaria sobre Discapacidad y DDHH (RID-CIN) y la conformación de la Red Interuniversitaria Latinoamericana y del Caribe sobre Discapacidad y Derechos Humanos.

Desde la RID-CIN, con representación de todas las universidades nacionales se trabaja desde hace más de 20 años para la institucionalización de políticas que garanticen la presencia, avance y egreso de las PcD. Solo, a modo ilustrativo, compartimos uno de sus documentos, sobre: Ampliación, 
profundización y operativización del Programa Integral de Accesibilidad para las Universidades Públicas (RID).

La Red, se constituyó en un espacio de referencia a nivel latinoamericano. Ante cualquier acto de discriminación o consulta es convocada para emitir opinión, (por ejemplo cuando Colombia elaboró las políticas de educación inclusiva la red fue consultada, o ante eventos de violencia y discriminación en Chile a fines del 2019 la red emitió una declaración. La red realiza encuentros bianuales, y tiene en su historia más de 5 publicaciones. Una de las últimas experiencias fue, en tiempos de pandemia, la recopilación de protocolos sobre accesibilidad a nivel latinoamericano.

Desde la RID-CIN se relevó información de las Universidades participantes que permitió realizar un análisis estadístico que describe la situación en las Universidades Nacionales en torno a ciertas dimensiones de la política universitaria de accesibilidad y discapacidad

La Red fue convocada a participar de la Conferencia Regional de Educación Superior (CRES) en Córdoba del 2018 y aportó un escrito para el documento final: "En la actualidad estamos siendo protagonistas de algunos incipientes pero alentadores cambios, como la inserción creciente de jóvenes y adultos, estudiantes, docentes y nodocentes con discapacidad, en la vida universitaria, y para ello la necesaria accesibilidad, tanto desde el punto de vista de la superación de barreras físicas, comunicacionales y académicas y la incorporación en la currícula de disciplinas universitarias ya sea con 
asignaturas, seminarios, cursos y/o contenidos de alguna unidad referidos a la temática de discapacidad. Las actividades de investigación y de extensión que favorecen la inclusión social y la afirmación de derechos de las personas con discapacidad, como contenidos básicos en los indicadores que hacen a la calidad de vida del conjunto de la comunidad. Es necesario que la educación sea la herramienta para promover el respeto y la defensa de los derechos humanos: el combate contra toda forma de discriminación, opresión y dominación; la lucha por la justicia social, la igualdad de género; la defensa y el enriquecimiento de los patrimonios culturales y ambientales; la seguridad y soberanía alimentaria y la erradicación del hambre y la pobreza; el diálogo intercultural con pleno respeto a las identidades; la promoción de una cultura de paz y cooperación. (Conferencia Regional de la Educación Superior en América Latina y el Caribe, 2018) .

El Programa Integral de Accesibilidad en las Universidades Públicas y su desarrollo en la UNLP.

La política universitaria de discapacidad / accesibilidad, desde el enfoque de derechos humanos y el modelo social de la discapacidad, plantea acciones transversales en toda la dinámica de la Universidad, promoviendo un cambio cultural que permita la construcción colectiva de una universidad dispuesta a democratizar el acceso al conocimiento, innovando y transformando sus políticas, el currículum, los servicios estudiantiles, la infraestructura física y 
administrativa y las estrategias de enseñanza, comunicación e información, bajo el paradigma de la accesibilidad en el entorno .

Desde la UNLP se trabajó en los tres componentes del Programa:

1. Accesibilidad física: Donde a través de talleres participativos entre áreas de planeamientos y personas con discapacidad elaboraron un registro de los aspectos necesarios a modificar para proyectar los Circuitos Mínimos Accesibles de cada una de las Facultades.

2. Accesibilidad comunicacional y equipamiento educativo: donde se hicieron entrega de equipamiento tecnológico (notebooks y periféricos) a aquellos estudiantes que se declararon en situación de discapacidad.

3. Accesibilidad Académica, que estuvo destinado a la capacitación de distintos actores de la comunidad universitaria. Este componente quedó enmarcado en lo que se denominó Políticas de Discapacidad para Estudiantes universitarios (PODES). Desde la UNLP desarrollaron actividades que tuvieron como destinatarias la comunidad universitaria: docentes, nodocentes y estudiantes de las 17 Unidades Académicas que conforman la UNLP y la Biblioteca Pública a través de talleres sobre la comunidad sorda, Jornada de fortalecimiento institucional destinada a Áreas Académicas, Capacitación a personal de la Guardia Edilicia de la UNLP, Capacitación sobre producción de materiales accesibles al personal de las bibliotecas; charla taller sobre ¿Qué implica una Comunicación Accesible?; Taller/Capacitación para los responsables de recibir y trabajar con los y las Ingresantes: ¿Qué necesitamos 
saber sobre el ingreso de estudiantes con discapacidad? $\mathrm{Y}$ como última actividad que selló el sentido que intentamos generar en cuanto a la construcción colectiva y el diálogo con las Organizaciones de la Sociedad Civil fue una jornada taller, donde se participó y aportó para la elaboración del informe alternativo para el Comité sobre los Derechos de las Personas con Discapacidad, (denominado SOMBRA), co-organizado por Red de Derechos de las $\mathrm{PcD}$ (REDI), con la participación de organizaciones de la sociedad Civil locales regionales y universidades de la región metropolitana. La actividad se encuentra dentro de las instancias informativas de la Convención de Derecho de las PcD, para ser presentado en el antes las Naciones Unidas.

Desde la Dirección de Inclusión, Discapacidad y DDHH, junto a la CUD se trabaja en diversas dimensiones, que intentan abarcar lo multidimensional y complejo de la vida universitaria. Solo a fines ilustrativos, porque excedería el desarrollo de cada uno, indicamos algunas de esas líneas de acción.

-Relevamiento y sistematización de los ingresantes que se autodeclaran en situación de discapacidad junto al pedido de apoyos. Trabajo que se actualiza y profundiza junto al Centro Superior para el Procesamiento de la Información (CeSPI) desde 2015.

- Jornada de capacitación al personal de atención al público y a responsables del ingreso estudiantil.

- Conformación de equipo de trabajo interdisciplinario en relación con la Comunidad Sorda. 
- Convocatorias y selección de intérpretes de lengua de señas.

- Cursos de español escrito como segunda lengua a la Comunidad Sorda.

- Cursos de lengua de señas

- Producción de documentos orientativos, elaborados junto a las personas que conviven con dicho diagnóstico: Dislexia, Condición psicosocial, Comunidad Sorda, hipoacúsicos, etc.

- Producción de materiales accesibles en tiempos de virtualidad.

- Publicaciones tanto de la UNLP como la participación en publicaciones nacionales, regionales y latinoamericanas.

-Teatro por la inclusión, con la participación de actrices sordas y ciegas. Obra de Teatro: Mujeres intensamente habitadas.

- Experiencias de transversalización / interseccionalidad: llevadas a cabo en el Museo de Ciencias Naturales. La noche de los museos; Cátedras, Encuentro Nacional de Mujeres.

- Participación y accesibilización en: Vení a la UNLP / Expouniversidad

- Equipo de Investigación

- Grupo de Testeo con la participación de estudiantes con discapacidad

- Intervención y elaboración de títulos en Braille, QR, libreta sanitaria, etc.

- Semana de la Discapacidad.

- Seminarios.

- Equipo de Trabajo Interbibliotecas (ETI).

- Participación en los cursos de ingreso. 
- Cursos de Braille y lengua de señas para los nodocentes.

- Creación de un blog: http://blogs.unlp.edu.ar/discapacidadunlp

Los avances alcanzados no llegan a saldar todos los obstáculos que al día de hoy aún persisten en la Universidad, es por ello que sigue siendo necesario generar políticas que atiendan las necesidades de las PcD desde una perspectiva integral, interdisciplinaria e interseccional. La dinámica social y su complejidad nos ponen en un movimiento constante donde siempre van surgiendo nuevos desafíos, porque también hemos aprendido, que las necesidades de las PcD no son homogéneas ni estáticas, sino que también van emergiendo singularidades que desafían las intervenciones ya realizadas.

Para poder seguir avanzando se elaboró una guía dinámica, ya que necesitamos seguir llevando la pregunta a todos los espacios institucionales, para que cada vez que se diseñe una política se piense que es posible que dentro de sus destinatarios/as puede haber una persona con discapacidad .

No queremos cerrar arbitrariamente este trabajo -ya que nos damos cuenta lo multidimensional e inabarcable que es-, sin dejar de mencionar otro aspecto que hace al compromiso ético y social de la Universidad que tiene que ver con la formación de nuevos perfiles profesionales, promoviendo la curricularización, formación, investigación y vinculación tecnológica en la temática, articulando con el diseño, planificación y ejecución de las decisiones políticas y académicas pertinentes, que contribuyan a hacer realidad una Universidad inclusiva y accesible, en pos de efectivizar los derechos humanos de todas las 
personas; en la redistribución de la riqueza no solo económica sino también educativa y cultural, comprendiendo globalmente las condiciones de vulnerabilidad relativas a la discapacidad.

Aunque trabajemos y podamos significar el avance en relación a la accesibilidad, sabemos que aún quedan barreras, y para cada uno/a de las estudiantes que se acerquen a la UNLP no le es tan significativo el porcentaje de avance si aún queda afuera.

\section{Bibliografía}

- Angelino, A y otros. Debates y perspectivas en torno a la discapacidad en América Latina. UNER. 2012

- CIN. Programa Integral de Accesibilidad en las Universidades Públicas. Profundización y avances en su implementación. Acuerdo Plenario № $798 / 11$

- Eroles Carlos, en UNIDIS (2009), I Encuentro Iberoamericano sobre Universidad y Discapacidad, Librería Uned, Madrid.

- FCE-UNLP Consideraciones generales para la inclusión de personas con discapacidad en la universidad. Facultad de Ciencias Económicas. 2015

- Katz, S; Danel, P y otros. Hacia una universidad accesible. Argentina: Universidad Nacional de la Plata. Comisión Universitaria sobre Discapacidad: de la génesis a la institucionalización. Edulp 2011. 
- Katz, S. y otros. Comisión Universitaria: Discapacidad y DDHH. Estado actual de las políticas de Educación Superior en las Universidades Nacionales Argentinas. Córdoba, 2011.

- Organización de Naciones Unidas, Convención sobre los derechos de las personas con discapacidad. 2006.

- Palacios, Agustina. El modelo social de discapacidad: orígenes, caracterización y plasmación en la Convención Internacional sobre los Derechos de las Personas con Discapacidad, Colección CERMI, Ediciones Cinca, Madrid 2008.

- Perez Lydia, Fernandez Moreno Aleida y Katz Sandra. Discapacidad en Latinoamérica. Voces y experiencias universitarias, Editorial de la Universidad Nacional de la Plata (Edulp) 2003.

- Tauber Fernando. Universidad Nacional de La Plata. Pensar la Universidad. 2018

- UNESCO-IESALC, 2018, Conferencia Regional de Educación Superior Universidad Nacional de educación a distancia. $1^{\circ}$ Encuentro iberoamericano

- sobre Universidad y Discapacidad. México 2009

- -Universidad Nacional de La Plata. Plan estratégico 2018-2022 